\title{
Risk Factors for Postoperative Retinal Detachment Following Cataract Surgery
}

\author{
Hamad Elzarrug1,2, Kevin M. Miller ${ }^{2}$, Yu Fei $^{2}$, Ahmed E. M. Daifalla ${ }^{3}$ \\ ${ }^{1}$ Ophthalmology Department, Faculty of Medicine, Benghazi University, Benghazi, Libya \\ ${ }^{2}$ Ophthalmology Department, Jules Stein Eye Institute, David Geffen School of Medicine at UCLA, Los Angelos, CA, USA \\ ${ }^{3}$ Ophthalmology Department, Faculty of Medicine, Benha University, Benha, Egypt \\ Email: olaharb2015@gmail.com
}

How to cite this paper: Elzarrug, H., Miller, K.M., Fei, Y. and Daifalla, A.E.M. (2019) Risk Factors for Postoperative Retinal Detachment Following Cataract Surgery. Open Journal of Ophthalmology, 9, 141-150. https://doi.org/10.4236/ojoph.2019.93015

Received: April 20, 2019

Accepted: August 25, 2019

Published: August 28, 2019

Copyright (c) 2019 by author(s) and Scientific Research Publishing Inc. This work is licensed under the Creative Commons Attribution International License (CC BY 4.0).

http://creativecommons.org/licenses/by/4.0/

cc) (i) Open Access

\begin{abstract}
Purpose: To determine the relation between patients' age and degree of myopia on the risk of postoperative retinal detachment following cataract surgery. Setting: University-based cataract referral practice. Patients and methods: This is a retrospective study. The chart of all patients in the practice of 1 surgeon (K.M.M) who had cataract surgery by the Kelman phacoemulsification technique between 1991 and 2010, were reviewed to identify patients (those who had retinal detachment) was associated with 4-control who didn't detach but had surgery around the same time. Result: Forty-three cases of retinal detachment were identified, the mean age at time of cataract surgery for the RD cases was $57.3 \pm 14.7$ years (range: 4 to 96 years) and for the control was $69.8 \pm 12.9$ years (range: 9 to 75 years), $\mathrm{p}<0.0001$, mean SE refraction error for the RD cases was $-4.8 \pm 4.7$ diopters of myopia and for the control group was $-1.6 \pm 4.3$ diopters of myopia $\mathrm{p}<0.0001$. Conclusion: The study shows that risk of retinal detachment and the degree of myopia is linear up to 12.00 diopters of myopia then starting to decline, and the risk of retinal detachment is the highest in age group between 50 to 59 years.
\end{abstract}

\section{Keywords}

Retinal Detachment, Cataract Surgery, Risk Factors, Myopia

\section{Introduction}

Cataract extraction (CE) is the most common surgical procedure performed in the United States in persons aged 65 years or older [1]. Increasingly, CE is performed in younger patients [2], and clear lens extraction for correction of refractive errors is gaining popularity [3]. Retinal detachment is one of the most significant and potentially blinding events that can occur after all forms of cataract 
surgery including phacoemulsification [4] [5]. Consequently, proper knowledge about and reliable estimate of the risk factors for pseudophakic retinal detachment are very important. Several risk factors have been reported in literature including preoperative factors (myopia, young age, and lattice degeneration), intraoperative complications (rupture of posterior capsule with or without vitreous loss) and postoperative factors (laser posterior capsulotomy) [5]-[11].

The purpose of this study is to determine the relationship between patients' age and degree of myopia on the risk of postoperative retinal detachment following cataract surgery. We were looking to investigate the concept that the risk of retinal detachment increases linearly with the degree of myopia and that age is relatively insignificant.

\section{Patients and Methods}

The institutional review board of University of California Los angles (UCLA) approved the protocol for the study of this cohort.

The study was based on a retrospective chart review of all patients who underwent Kellman phacoemulsification (KPE) between July 1991 and December 2010, performed at one institution "Jules Stein Eye Institute" (JSEI), UCLA. These were done by one surgeon (KMM). Charts were reviewed to identify eyes that experienced retinal detachment after KPE. Those who had cataract surgery done else where and experienced retinal detachment were excluded. Each study patient, who had retinal detachment, was associated with 4 control patients who did not detach but had KPE around the same time. Those were selected as the two cases before and the two cases after the study patient.

The information collected from the medical records included; demographic data, preoperative ophthalmic examination data specially spherical equivalent refractive error, axial length, IOL power, history of previous surgery, surgical details, and whether a neodymium: yttrium-aluminum-garnet (Nd:YAG) laser capsulotomy was performed postoperatively. In addition, record of retinal detachment occurrence, its onset following cataract surgery, and the length of the follow up.

The relative importance of age, spherical equivalent refractive error, axial length, IOL power, and (Nd:YAG) laser capsulotomy, was evaluated using the Wilcoxon signed rank test. A significance level of $5 \%$ was considered significant throughout the study.

\section{Results}

Medical record review identified 43 eyes that experienced retinal detachment after cataract surgery. These were identified as group 1 . The control group, group 2 , included 172 eyes, which had cataract surgery within the same operative conditions and did not suffer retinal detachment postoperatively.

Demographic characteristics between eyes of group 1 and group 2 are shown in Table 1. Male sex was a significant risk factor, as $31(72 \%)$ patients of group 1 $(\mathrm{RD})$ were males with high significance $(\mathrm{p}=0.001)$ using Fisher exact test. Other 
Table 1. Demographic and history characteristics between eyes of Group 1 and Group 2.

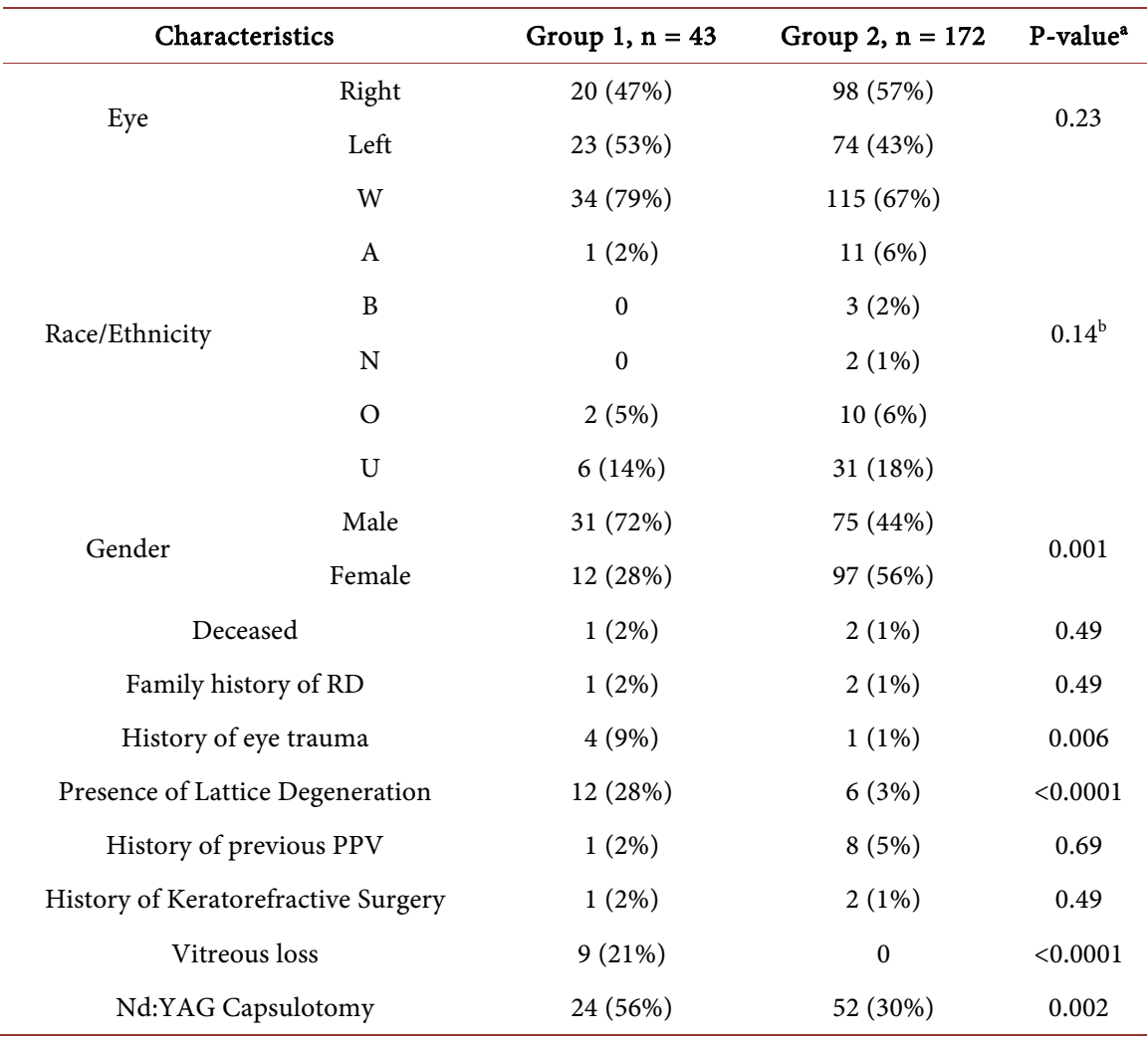

a: Fisher exact test. b: Comparing white to non-white.

risk factors shown to be highly significant $(\mathrm{p}<0.0001)$ were the history of lattice retinal degeneration and the occurrence of intraoperative vitreous loss. Also it was found that a history of ocular trauma and postoperative (Nd:YAG) laser capsulotomy are significant with $P$ values of 0.006 and 0.002 respectively. On the other hand, several factors were found insignificant including; laterality, ethnicity, family history of retinal detachment, as well as past ocular history of PPV or keratorefractive surgery.

In order to analyze the age as a risk factor for $\mathrm{RD}$ after cataract surgery, all subjects enrolled in the study were subdivided according to their age as shown in Table 2 and Figure 1. It was noticed that the risk of $\mathrm{RD}$ among group 1 patients aged 50 - 59 years and 60 - 69 years were the highest (34\% and 29\% respectively). They together comprised $58 \%$ of the total number of cases of RD. The mean age at time of cataract surgery for the retinal detachment cases (group 1) was $57.3 \pm$ 14.7 years (range: 9 to 75), and the mean age for the controls (group 2) was $69.8 \pm$ 12.8 years (range: 4 to 96 years) with $\mathrm{p}<0.0001$ using Wilcoxon rank test, as shown in Table 5.

The effect of degree of myopia was studied in a similar way, as the two groups were compared according to the amount of preoperative spherical equivalent (SE), which was subdivided into 8 subgroups as shown in Table 3. It was noted that the risk of $\mathrm{RD}$ is directly proportional to SE up to -12.00 diopters, after which this risk declines. Also a statistically significant difference $(p=0.0007)$ 
Table 2. Comparison of group 1 and group 2 regarding age subgroups.

\begin{tabular}{ccccccc}
\hline Case Group & \multicolumn{3}{c}{ Group 1 $(\mathrm{n}=43)$} & \multicolumn{3}{c}{ Group 2 $(\mathrm{n}=172)$} \\
\cline { 2 - 7 } $\begin{array}{c}\text { Age Subgroup } \\
\text { (years) }\end{array}$ & $\mathrm{n}$ & $\begin{array}{c}\text { \% to total } \\
\text { of group } \\
\text { < }\end{array}$ & $\begin{array}{c}\text { \% to total } \\
\text { of age } \\
\text { subgroup }\end{array}$ & $\mathrm{n}$ & $\begin{array}{c}\text { \% to total } \\
\text { of group 2 }\end{array}$ & $\begin{array}{c}\% \text { to total } \\
\text { of age } \\
\text { subgroup }\end{array}$ \\
\hline 40 & 4 & 9.3 & 66.7 & 2 & 1.2 & 33.3 \\
$40-49$ & 5 & 11.6 & 31.2 & 11 & 6.4 & 68.8 \\
$50-59$ & 11 & 25.6 & 34.4 & 21 & 12.2 & 65.6 \\
$60-69$ & 14 & 32.6 & 28.6 & 35 & 20.3 & 71.4 \\
$70-79$ & 9 & 21 & 12.7 & 62 & 36 & 87.3 \\
$\geq 80$ & 0 & 0 & 0 & 41 & 32.8 & 100 \\
\hline
\end{tabular}

Cochran-armitage trend test $\mathrm{p}<0.0001$.

Table 3. Comparison of Group 1 and Group 2 regarding spherical equivalent (SE) subgroups.

\begin{tabular}{|c|c|c|c|c|c|c|}
\hline \multirow[b]{2}{*}{$\begin{array}{l}\text { SE Subgroup } \\
\text { (Diopters) }\end{array}$} & \multicolumn{3}{|c|}{ Group $1(\mathrm{n}=40)$} & \multicolumn{3}{|c|}{ Group $2(n=163)$} \\
\hline & $\mathrm{n}$ & $\begin{array}{c}\% \text { to total } \\
\text { of group } \\
1\end{array}$ & $\begin{array}{l}\% \text { to total } \\
\text { of SE } \\
\text { subgroup }\end{array}$ & $\mathrm{n}$ & $\begin{array}{l}\% \text { to total } \\
\text { of group } 2\end{array}$ & $\begin{array}{c}\% \text { to total } \\
\text { of SE } \\
\text { subgroup }\end{array}$ \\
\hline$\geq 0.00$ & 6 & 15 & 7.9 & 70 & 43 & 92.1 \\
\hline-0.25 to -2.00 & 6 & 15 & 14.3 & 36 & 22 & 85.7 \\
\hline-2.25 to -4.00 & 7 & 17.5 & 21.2 & 26 & 16 & 78.8 \\
\hline-4.25 to -6.00 & 9 & 22.5 & 42.8 & 12 & 7.3 & 57.2 \\
\hline-6.25 to -8.00 & 3 & 7.5 & 37.5 & 5 & 3 & 62.5 \\
\hline-8.25 to -10.00 & 3 & 7.5 & 42.9 & 4 & 2.5 & 57.1 \\
\hline-10.25 to -12.00 & 2 & 5.0 & 50 & 2 & 1.2 & 50 \\
\hline$\leq 12.25$ & 4 & 10 & 33.3 & 8 & 5 & 66.7 \\
\hline
\end{tabular}

Cochran-Armitage trend test $\mathrm{p}=0.0007$.

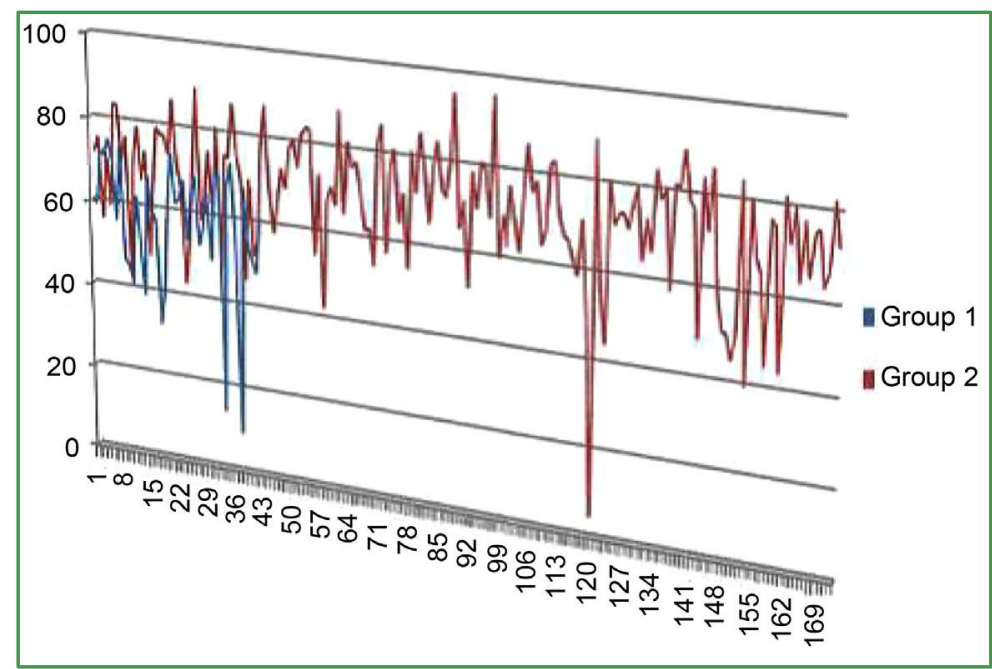

Figure 1. Chart blot of age of patients of groups 1 and 2 at the time of KPE. 
was found between group 1 and group 2 regarding preoperative SE. However, all nine eyes of vitreous loss had RD. Thus the data were further filtered and those nine eyes were excluded to eliminate vitreous loss as a confounding factor. Table 4 and Figure 2 show comparison of groups 1 and 2 regarding preoperative SE after excluding those 9 cases. It showed more linear direct relationship of risk of postoperative $\mathrm{RD}$ and degree of myopia.

The mean preoperative spherical equivalent refractive error for group 1 eyes was $-4.8 \pm 4.7$ diopter (D), and for the group 2 was $-1.5 \pm 4.3$ (D), with $\mathrm{p}<$ 0.0001 by Wilcoxon rank test. Also, the mean preoperative axial length for group 1 eyes was $25.7 \pm 1.8 \mathrm{~mm}$ and for group 2 eyes was $24.1 \pm 1.7 \mathrm{~mm}$, with $\mathrm{p}<$ 0.0001 by Wilcoxon rank test. The mean preoperative IOL power for group 1 eyes was $15.6 \pm 4.9$ (D), and for group 2 was $19.4 \pm 4.8$ (D), with $\mathrm{p}<0.0001$ by Wilcoxon rank test, as shown in Table 5.

Table 4. Comparison of group 1 and group 2 regarding spherical equivalent (SE) subgroups, after excluding 9 cases of vitreous loss.

\begin{tabular}{lcccccc}
\hline \multicolumn{1}{c}{ Case Group } & \multicolumn{3}{c}{ Group 1 $(\mathrm{n}=31)$} & \multicolumn{2}{c}{ Group 2 (n=163) } \\
\cline { 2 - 7 } $\begin{array}{l}\text { SE Subgroup } \\
\text { (Diopters) }\end{array}$ & $\mathrm{n}$ & $\begin{array}{c}\text { \% to total } \\
\text { of group } \\
1\end{array}$ & $\begin{array}{c}\text { \% to total } \\
\text { of SE } \\
\text { subgroup }\end{array}$ & $\mathrm{n}$ & $\begin{array}{c}\text { \% to total } \\
\text { of group }\end{array}$ & $\begin{array}{c}\text { \% to total of } \\
\text { SE subgroup }\end{array}$ \\
\hline 0.00 & 5 & 16.1 & 6.7 & 70 & 43 & 93.3 \\
-0.25 to -2.00 & 6 & 19.4 & 14.3 & 36 & 22 & 85.7 \\
-2.25 to -4.00 & 6 & 19.4 & 18.7 & 26 & 16 & 81.3 \\
-4.25 to -6.00 & 3 & 9.7 & 20 & 12 & 7.3 & 80 \\
-6.25 to -8.00 & 3 & 9.7 & 37.5 & 5 & 3 & 62.5 \\
-8.25 to -10.00 & 3 & 9.7 & 42.9 & 4 & 2.5 & 57.1 \\
-10.25 to -12.00 & 2 & 6.5 & 50 & 2 & 1.2 & 50 \\
$\geq 12.25$ & 3 & 9.7 & 27.3 & 8 & 5 & 72.7 \\
\hline
\end{tabular}

Cochran-armitage trend test $\mathrm{p}=0.003$.

Table 5. Summary of statistics of variables between group 1 and group 2 cases.

\begin{tabular}{|c|c|c|c|c|c|c|c|}
\hline \multirow{2}{*}{ Variable } & \multicolumn{3}{|c|}{ Group $1(n=43)$} & \multicolumn{3}{|c|}{ Group $2(\mathrm{n}=172)$} & \multirow{2}{*}{$\begin{array}{l}\mathrm{P}^{* * *} \\
\text { Value }\end{array}$} \\
\hline & Mean $\pm \mathrm{SD}^{*}$ & Range & Median & Mean $\pm \mathrm{SD}^{*}$ & Range & Median & \\
\hline Age at KPE (years) & $57.4 \pm 14.7$ & 9 to 75 & 60 & $69.8 \pm 12.9$ & 9 to 96 & 72 & $<0.0001$ \\
\hline SE-RE (Diopter) & $-4.8 \pm 4.7$ & -18.5 to 1.5 & -4.00 & $-1.6 \pm 4.3$ & -21 to 9.8 & -0.5 & $<0.0001$ \\
\hline $\begin{array}{l}\text { Axial Length } \\
\quad(\mathrm{mm})\end{array}$ & $25.7 \pm 1.8$ & 21.9 to 33.3 & 25.6 & $24.1 \pm 1.7$ & $\begin{array}{c}20.2 \text { to } \\
32.2\end{array}$ & 23.7 & $<0.0001$ \\
\hline $\begin{array}{l}\text { IOL Power } \\
\text { (Diopter) }\end{array}$ & $15.6 \pm 4.9$ & $\begin{array}{c}-1.00 \text { to } \\
24.5\end{array}$ & 15.3 & $19.4 \pm 4.8$ & -1.0 to 34 & 20 & $<0.0001$ \\
\hline $\begin{array}{l}\text { Duration } \\
\text { (months) }^{* *}\end{array}$ & $30.2 \pm 37.1$ & 0.2 to 153 & 12.1 & $32.2 \pm 35.2$ & 0.0 to 162 & 18.7 & $=0.64$ \\
\hline
\end{tabular}

${ }^{*} \mathrm{SD}=$ Standard Deviation. ${ }^{*}$ Duration (months) $=$ Duration of time interval between KPE and RD in group1 and duration of follow up period in group $2 .{ }^{* *} \mathrm{P}$ Values $=$ Wilcoxon signed rank test p-values. 


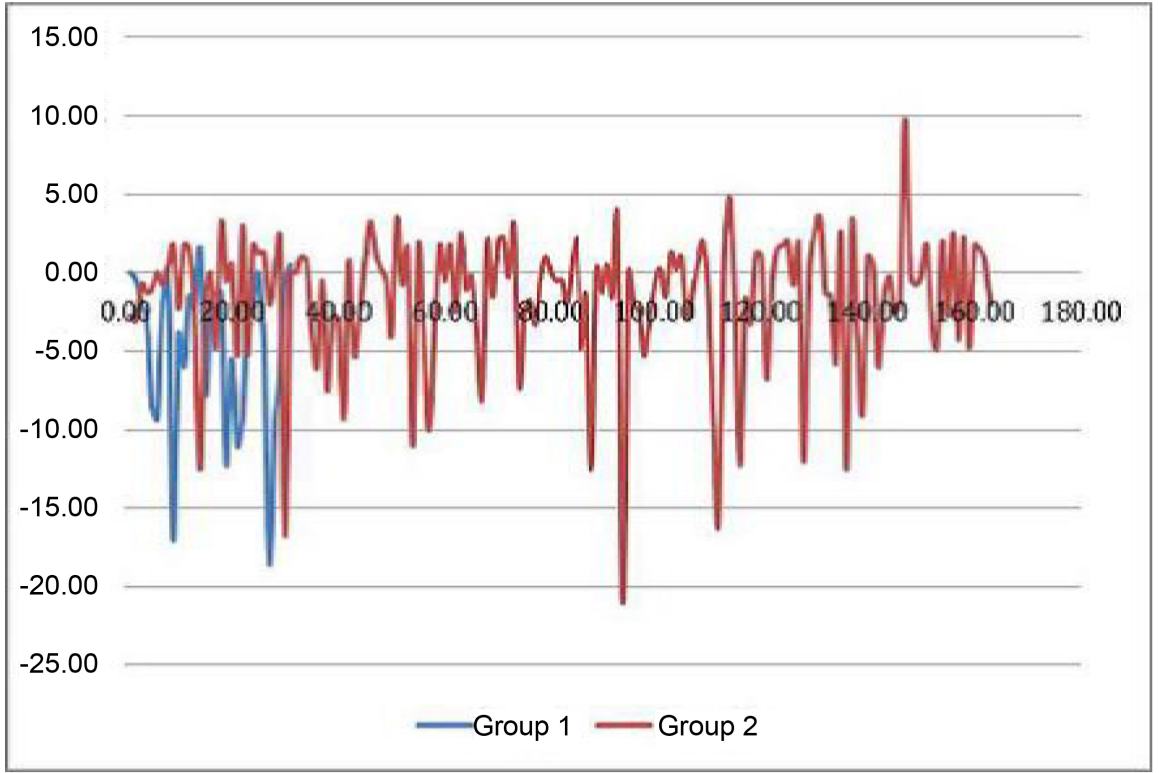

Figure 2. Chart blot of SE-RE of eyes of groups 1 and 2, after excluding eyes of vitreous loss.

Mean follow-up duration between the date of KPE and onset of RD among group 1 eyes was $30.2 \pm 37.1$ months. The mean follow-up duration for group 2 eyes was $32.2 \pm 35.2$ months. They showed statistically insignificant difference $(\mathrm{P}=$ 0.64) using Wilcoxon signed rank test, Table 5.

\section{Discussion}

In the past twenty years, Kelman phacoemulsification (KPE) has become the preferred technique for cataract surgery in the developed world [12]. Although $\mathrm{KPE}$ has been found to reduce the overall complication rate of cataract surgery, the rate of rhegmatogenous retinal detachment (RRD) after cataract surgery has not been reduced significantly by the shift to phacoemulsification [13] [14]. RRD is a serious and potentially sight threating complication that can be major personal disaster to patient's. Certain risk factors such as posterior capsular rupture (PCR) and other intraoperative complications have long been identified for pseudophakic retinal detachment. Recent studies confirm these risk factors and further analyze others such as male sex, younger age and myopia.

We have performed a study of retinal detachment after cataract surgery based on clinical records. We were able to collect information on potential risk factors such as male sex, young age at KPE, long axial length, myopia and surgical complications.

Similar to most of the previous studies, male sex was found to be a significant risk factor, where 31 (72\%) out of 43patients of group 1 (RRD) were males. Tuft et al. reported that males had a significantly higher risk of retinal detachment compared with females [11]. Russell et al., found that the incidence of RRD was higher in men $(2.1 \%)$ than in women (0.62\%) [15], while Erie et al. reported that men were 2.9 times more likely to have RRD than women [16]. Also Sheu et al. 
found that cumulative 6-years $\mathrm{RD}$ rates were $1.90 \%$ in the male subgroup and $0.56 \%$ in the female subgroup [17].

In the recent study we noticed that the higher occurrence of RRD after KPE was among patients aged between 50 - 59 years and 60 - 69 years, where they together comprised $58 \%$ of all RRD cases. This finding is consistent with other reports. Tuft et al. ${ }^{11}$ found that younger age was significantly associated with a higher risk of RRD with a linear relationship. Russell et al. reported the risk for RRD 5.17\% in those patients younger than 50 years compared with $0.64 \%$ for those patients older than 70 years [15], while Erie et al found that each 10 years decrease in age resulted in a 1.6-fold increase of RRD and cases $<60$ years of age at the time of cataract extraction were 6 times more likely to have RRD than those $\geq 60$ years [16]. The results of Sheu et al. confirmed that age below 50 years at the time of cataract extraction was significant risk factor for RRD [17]. The prevalence of posterior vitreous detachment (PVD), which limits the transmission of forces of cataract extraction through the vitreous to the retina, and the higher incidence of vitreous degenerative change, among older patients seem to have a protective rule against $\mathrm{RRD}$. On the other hand, pre-senile cataracts are usually associated with more ocular anomalies that may predispose to RRD.

Myopia increased the risk of retinal detachment compared with hyperopia, and eyes with refraction between 0 - 4 diopters of myopia consisted the highest percentage of retinal detachment in our study. The mean preoperative spherical equivalent refractive error for group 1 eyes was -4.8 (D), and for the group 2 was $-1.5(\mathrm{D})$, and similarly the mean preoperative axial lengths were $25.7 \mathrm{~mm}$ and $24.1 \mathrm{~mm}$ respectively. Our findings are more or less the same as previous studies. One study showed a four-fold increase in spontaneous retinal detachment risk for refractive error of -1.00 to $-3.00 \mathrm{D}$ and myopia over $-3.00 \mathrm{D}$ was found to have a 10-fold higher risk of retinal detachment [18]. Russell et al. found that the risk for RRD was 4.9 times higher in eyes that had an axial lens measurement $\geq 24 \mathrm{~mm}$ [15]. Tuft et al. reported that axial length $>23 \mathrm{~mm}$ was a significant risk factor for RRD and suggested a three-fold increase in risk independent of the other risk factors [11]. Sheu et al. found that moderate myopia $(26 \mathrm{~mm}>\mathrm{AL}>23 \mathrm{~mm})$ appeared as a significant risk factor for RRD after cataract surgery [17], but they reported that the statistical significant of high myopia ( $\mathrm{AL}>26 \mathrm{~mm}$ ) was extremely high.

After excluding eyes that had suffered vitreous loss during KPE, it was found that 12 out of the remaining 31 eyes (38.7\%) had preoperative SE between -0.25 and $-4.00 \mathrm{D}$, and 11 (35.5\%) between -4.25 and $-12.00 \mathrm{D}$. Only 3 eyes (9.7\%) had SE greater than $-12.00 \mathrm{D}$. This means that in our series the risk of RRD after KPE was more frequent with mild to moderate degrees of myopia, contrary to other previous reports. Our explanation is that the early PVD and vitreous gel liquefaction (synchisis) frequently seen in highly myopic eyes appears to protect the retina from the micro dynamic changes of the anterior vitreous during KPE procedure. 
We have found that posterior capsular tear with vitreous loss during KPE was a significant risk factor for RRD post operatively, where 9 eyes (21\%) out of 43 eyes of group 1 had this intraoperative complication. This is comparable with the results of Russell et al who reported 4 eyes had RRD out of 33 eyes that had intraoperative posterior capsular rupture [15]. Also Desi et al. [19], Ionides et al. [20], Tuft et al. [11], Erie et al. [16], Bhagwandien et al. [5], all these reports had concluded that posterior capsule tear at cataract surgery was a significant risk factor for subsequent RRD.

Similar to some previous studies, our study has revealed that history of $\mathrm{Nd}$ : YAG laser posterior capsulotomy in the postoperative period is a statistically significant risk ( $p=0.002)$ for the subsequent development of RRD [6] [7] [21] [22] [23]. However, other nicely designed studies conflict regarding this association, reporting minimal insignificant or no effect [5] [8] [11] [15] [16] [17] [24].

\section{Conclusion}

This retrospective study confirms the effect of some previously identified risk factors such as age, axial length and degree of myopia in the development of retinal detachment after cataract surgery. It also emphasizes the importance of surgical events such as posterior capsule tear and vitreous loss in contributing to retinal detachment. In cases of capsular or zonular rupture, all mean, including prophylactic vitrectomy of vitreal strands, should be used to avoid permanent vitreous traction, therefore reducing the risk of retinal detachment.

\section{Conflicts of Interest}

The authors declare no conflicts of interest regarding the publication of this paper.

\section{References}

[1] West, E.S., Behrens, A., McDonnell, P.J., et al. (2005) The Incidence of Endophthalmitis after Cataract Surgery among the U.S. Medicare Population Increased between 1994 and 2001. Ophthalmology, 112, 1388-1394.

https://doi.org/10.1016/j.ophtha.2005.02.028

[2] Baratz, K.H., Gray, D.T., Hodge, D.O., et al. (1997) Cataract Extraction Rates in Olmsted County, Minnesota, 1980 through 1994. Archives of Ophthalmology, 115, 1441-1446. https://doi.org/10.1001/archopht.1997.01100160611015

[3] Colin, J., Robinet, A. and Cochener, B. (1999) Retinal Detachment after Clear Lens Extraction for High Myopia: Seven-Year Follow-Up. Ophthalmology, 106, 2281-2284. https://doi.org/10.1016/S0161-6420(99)90526-2

[4] Boberg-Ans, G., Villumsen, J. and Henning, V. (2003) Retinal Detachment after Phacoemulsification Cataract Extraction. Journal of Cataract \& Refractive Surgery, 29, 1333-1338. https://doi.org/10.1016/S0886-3350(03)00057-9

[5] Bhagwandien, A.C.E., Cheng, Y.Y.Y., Wolfs, R.C.W., van Meurs, J.C. and Luyten, G.P.M. (2006) Relationship between Retinal Detachment and Biometry in 4262 Cataractous Eyes. Ophthalmology, 113, 643-649.

https://doi.org/10.1016/j.ophtha.2005.10.056 
[6] Javitt, J.C., Tielsch, J.M., Canner, J.K., Kolb, M.M., Sommer, A. and Steinberg, E.P. (1992) National Outcomes of Cataract Extraction. Increased Risk of Retinal Complications Associated with Nd: YAG Laser Capsulotomy. The Cataract Patient Outcomes Research Team. Ophthalmology, 99, 1487-1497.

https://doi.org/10.1016/S0161-6420(92)31775-0

[7] Powell, S.K. and Olsen, R.J. (1995) Incidence of Retinal Detachment after Cataract Surgery and Neodymium YAG Laser Capsulotomy. Journal of Cataract \& Refractive Surgery, 21, 132-135. https://doi.org/10.1016/S0886-3350(13)80499-3

[8] Olsen, G. and Olson, R.J. (2000) Update on a Long-Term, Prospective Study of Capsulotomy and Retinal Detachment Rates after Cataract Surgery. Journal of Cataract \& Refractive Surgery, 26, 1017-1021. https://doi.org/10.1016/S0886-3350(00)00304-7

[9] Nissen, K.R., Fuchs, J., Goldschmidt, E., Anderson, C.U., Bjerrum, K., Corydon, L., Degn, T., et al. (1998) Retinal Detachment after Cataract Extraction in Myopic Eyes. Journal of Cataract \& Refractive Surgery, 24, 772-776. https://doi.org/10.1016/S0886-3350(98)80129-6

[10] Ripandelli, G., Scassa, C., Parisi, V., Gazzaniga, D., D’Amico, D.J. and Stirpe, M. (2003) Cataract Surgery as a Risk Factor for Retinal Detachment in Very Highly Myopic Eyes. Ophthalmology, 110, 2355-2361. https://doi.org/10.1016/S0161-6420(03)00819-4

[11] Tuft, S.J., Minassian, D. and Sullivan, P. (2006) Risk Factors for Retinal Detachment after Cataract Surgery: A Case-Control Study. Ophthalmology, 113, 650-656. https://doi.org/10.1016/j.ophtha.2006.01.001

[12] Apple, D.J., Ram, J., Foster, A. and Peng, Q. (2000) Elimination of Cataract Blindness: A Global Perspective Entering the New Millennium. Survey of Ophthalmology, 45, S1-S196. https://doi.org/10.1016/S0039-6257(00)00186-7

[13] Seward, H.C., Dalton, R. and Davis, A. (1993) Phacoemulsification during the Learning Curve: Risk/Benefit Analysis. Eye, 7, 164-168. https://doi.org/10.1038/eye.1993.35

[14] Tarbet, K.J., Mamalis, N., Theurer, J., et al. (1995) Complication and Results of Phacoemulsification Performed by Residents. Journal of Cataract \& Refractive Surgery, 21, 661-665. https://doi.org/10.1016/S0886-3350(13)80562-7

[15] Russell, M., Gaskin, B., Russell, D. and Polkinghrone, P.J. (2006) Pseudophacic Retinal Detachment after Phacoemulsification Cataract Surgery: Ten-Year Retrospective Review. Journal of Cataract \& Refractive Surgery, 32, 442-445. https://doi.org/10.1016/j.jcrs.2005.12.095

[16] Erie, J.C., Raecker, M.A., Baratz, K.H., Schleck, C.D., Burke, J.P. and Roberston, D.M. (2006) Risk of Retinal Detachment after Cataract Extraction, 1980-2004: A Population-Based Study. Ophthalmology, 113, 2026-2032. https://doi.org/10.1016/j.ophtha.2006.05.054

[17] Sheu, S.J., Ger, L.P. and Chen, J.F. (2007) Male Sex as a Risk Factor for Pesudophakic Retinal Detachment after Cataract Extraction in Taiwanese Adult. Ophthalmology, 114, 1898-1903. https://doi.org/10.1016/j.ophtha.2007.02.030

[18] Eye Disease Case-Control Study Group (1993) Risk Factors for Idiopathic Rhegmatogenous Retinal Detachment. American Journal of Epidemiology, 137, 749-757. https://doi.org/10.1093/oxfordjournals.aje.a116735

[19] Desai, P., Minassian, D.C. and Reidy, A. (1999) National Cataract Surgery Survey 1997-8: A Report of the Results of Clinical Outcomes. British Journal of Ophthalmology, 83, 1336-1340. https://doi.org/10.1136/bjo.83.12.1336 
[20] Ionides, A., Minassian, D. and Tuft, S. (2001) Visual Outcome Following Posterior Capsular Rupture during Cataract Surgery. British Journal of Ophthalmology, 85, 222-224. https://doi.org/10.1136/bjo.85.2.222

[21] Tielsch, J.M., Legro, M.W., Cassard, S.D., et al. (1996) Risk Factors for Retinal Detachment after Cataract Surgery: A Population-Based Case-Control Study. Ophthalmology, 103, 1537-1545. https://doi.org/10.1016/S0161-6420(96)30465-X

[22] Lois, N. and Wong, D. (2003) Pseudophakic Retinal Detachment. Survey of Ophthalmology, 48, 467-487. https://doi.org/10.1016/S0039-6257(03)00083-3

[23] Aslam, T.M., Devlin, H. and Dhillon, B. (2003) Use of Nd:YAG Laser Capsulotomy. Survey of Ophthalmology, 48, 594-612.

https://doi.org/10.1016/j.survophthal.2003.08.002

[24] Nielsen, N.E. and Naeser, K. (1993) Epidemiology of Retinal Detachment Following Extracapsular Cataract Extraction: A Follow-Up Study with an Analysis of Risk Factors. Journal of Cataract \& Refractive Surgery, 19, 675-680.

https://doi.org/10.1016/S0886-3350(13)80333-1 